\title{
АКТУАЛЬНЫЕ ПРОБЛЕМЫ СОХРАНЕНИЯ ЗДОРОВЬЯ ПОДРОСТКОВ В РЕГИОНЕ: МОНИТОРИНГ И ПУТИ РЕШЕНИЯ
}

\author{
(С Елисеева Ю.В., Дубровина Е.А., Елисеев Ю.Ю.
}

Кафедра общей гигиены и экологии

Саратовского государственного медицинского университета им. В.И. Разумовского, Саратов

E-mail: eliseeva-gig@mail.ru

\begin{abstract}
Проанализированы показатели заболеваемости, медико-социальные факторы, образ жизни современных подростков 15-17 лет из различных образовательных учреждений г. Саратова. Показано увеличение уровня первичной заболеваемости подростков за период 2006-2015 гг. на 30,5\%. Более высокий уровень заболеваемости по обращаемости выявлен среди девушек общеобразовательных школ. Определены различия в структуре хронических заболеваний, выявленных при углубленном медицинском осмотре подростков, обучающихся в школах и профессиональном техникуме. В сравнительном аспекте изучены жилищно-бытовые условия, особенности питания, организация досуга и распространенность вредных привычек у учащихся различных учебных заведений.
\end{abstract}

Ключевые слова: подростки, заболеваемость, медико-социальные факторы, образ жизни.

\section{URGENT PROBLEMS OF PRESERVING TEENAGERS' HEALTH IN THE REGION: MONITORING AND SOLUTIONS}

Eliseeva Yu.V., Dubrovina E.A., Eliseev Yu.Yu.

Department of General Hygiene and Ecology of V.I. Razumovsky Saratov State Medical University, Saratov

The morbidity, medical and social factors, and lifestyle of modern teenagers aged $15-17$ from different educational institutions of Saratov were analyzed. The increase in the teenagers' initial morbidity made up 30.5\% within 2006-2015. A higher level of morbidity according to appealability was revealed among comprehensive schoolgirls. The differences in the structure of chronic diseases detected during the thorough medical examination of teenagers enrolled in comprehensive and vocational schools were brought out. Living conditions, eating habits, leisure activities, and incidence of harmful habits among students of various educational institutions were comparatively investigated.

Keywords: teenagers, incidence, medical and social factors, lifestyle.

Охрана здоровья детей, подростков и молодежи рассматривается в качестве одной из стратегических задач общества и государства, подразумевающей концентрирование на предотвращении возникновения и прогрессирования заболеваний и иных отклонений. Изменения в состоянии здоровья детей и подростков во всем мире имеют негативные тенденции $[1,9,12,15,16]$. Ситуация в России также вызывает наибольшие опасения, поскольку в последние годы здоровье подрастающего поколения стремительно ухудшается и рассматривается как угрожающее национальной безопасности страны $[1,11]$. Наибольшее распространение морфо-функциональных отклонений и хронических заболеваний, включая социально значимую патологию, отмечается среди современных подростков [2, 5, 7].

Состояние здоровья подростков в большей своей части обусловлено действием социальных условий и поведенческими факторами риска [8, $10,12]$. Среди факторов, отрицательно влияющих на состояние здоровья учащейся молодежи, выделяют неполноценное питание, гиподинамию, вредные привычки, раннюю социализацию, беспорядочные половые связи, неполные семьи, насилие в семье и др. $[3,6,13,14]$. В подростко- вом возрасте активно формируются и закрепляются жизненные ценности, которые по мере взросления определяют здоровье молодых людей, а также здоровье общества в целом. В связи с этим для любого региона страны анализ заболеваемости населения подросткового возраста является актуальной социально-демографической проблемой, а ее тенденции и причины - объектом пристального изучения.

Цель исследования - провести анализ взаимосвязи заболеваемости, образа жизни и процессов формирования гигиенической активности у подростков различных учебных заведений.

\section{МАТЕРИАЛЫ И МЕТОДЫ ИССЛЕДОВАНИЯ}

Для анализа данных о заболеваемости подростков по обращаемости, в том числе выявленной впервые, использована отчетная статистическая форма № 12 «Сведения о числе заболеваний, зарегистрированных у больных, проживающих в районе обслуживания лечебного учреждения» государственного учреждения здравоохранения «Медицинский информационно-аналитический центр» Минздрава Саратовской области. Анализ 
патологической пораженности подростков проводился на основании выкопировки данных результатов углубленных медицинских осмотров из Ф. 026/У-2000. В дальнейшем проводилось распределение выявленных функциональных отклонений и хронических заболеваний по классам болезней согласно «Международной статистической классификацией болезней и проблем, связанных со здоровьем» (десятый пересмотр). Проводили анализ хронической заболеваемости подростков с учетом ее распространенности.

Анализ медико-социальных факторов и образа жизни проводился на основании анкетирования 15-17-летних учащихся трех общеобразовательных школ (489 человек) и учебного заведения среднего профессионального образования на речном транспорте (290 человек). Выбор учебных организаций для исследования осуществлялся из числа тех, в которых руководители и родительский комитет одобрили участие учащихся в исследовании. Проводимые исследования не ущемляли прав и соответствовали требованиям биомедицинской этики. В ходе анкетного опроса изучены жилищно-бытовые условия, организация режима дня, особенности режима и характера питания, двигательная активность, поведенческие факторы риска.

Статистический анализ включал расчет относительных и средних величин, оценку их достоверности с помощью параметрических (критерий Стъюдента t) и непараметрических критериев (критерий согласия $-\chi^{2}$ ). Критерием достоверности различий считалось достижение уровня значимости $p<0,05$. Для установления корреляционных взаимосвязей рассчитывался коэффициент ранговой корреляции Спирмена.

\section{РЕЗУЛЬТАТЫ ИССЛЕДОВАНИЯ И ИХ ОБСУЖДЕНИЕ}

Проведенный анализ состояния здоровья подрастающего поколения Саратовской области подтвердил сохранение негативных медикодемографических тенденций в регионе. Численность детского населения от 0 до 17 лет за период с 2011 г. по 2015 г. сократилась на 28,7 тыс. человек. По состоянию на 2015 г. в Саратовской области проживали 494,6 тыс. подростков в возрасте 15-19 лет, что составило 19,8\% от всего населения.

Несмотря на принятую в Саратовской области систему мер профилактики, диагностики и лечения заболеваний, статистические показатели, характеризующие здоровье подрастающего поколения, свидетельствуют о сохранении высокого уровня заболеваемости детей и подростков [4]. В течение 10 лет (2006-2015 гг.) отмечено увеличе- ние уровня первичной заболеваемости подросткового населения на 30,5\% (с 1118,5 до 1460,1 на 1000 подростков); пик заболеваемости за последние 10 лет пришелся на 2012 г. (1499,0 на 1000 подростков). В структуре первичной заболеваемости подростков первое место занимали болезни органов дыхания (44\%), второе - травмы, отравления $(11 \%)$, третье - болезни мочеполовой системы (7\%), четвертое - заболевания кожи и подкожной клетчатки, органов пищеварения, органа зрения (по 5\%).

Изучение заболеваемости подростков, обучающихся в различных городских учебных заведениях, показало вариативность показателей в сравниваемых группах учащихся. Так, среди школьников уровень заболеваемости по данным обращаемости составил в группе учащихся 15 лет 1505,4\%o, 16 лет - 1409,1\%о, 17 лет - 1535,1\%. В группе подростков техникума наибольший уровень заболеваемости по обращаемости отмечен среди 15-летних лиц и составил на 1-м курсе 1449,6\%о, на 2-м курсе - 995,7\%о, на 3-м курсе $1135,2 \%$. Отмечено, что независимо от вида учебного заведения заболеваемость у юношей имела тенденцию к небольшому снижению с возрастом учащихся; у девушек, напротив, регистрировался рост показателя на 9,5-10,8\% (p>0,05). В целом уровень заболеваемости по обращаемости среди девушек был в 1,2-1,4 раза выше, чем среди юношей.

В структуре заболеваемости по обращаемости среди подростков первое место традиционно занимали болезни органов дыхания, второе - органов пищеварения (у школьников), травмы (у учащихся техникума). Также среди учащихся профессионального техникума отмечен высокий уровень распространенности болезней кожи и подкожной клетчатки, нервной системы (преимущественно расстройства вегетативной нервной системы), уха и сосцевидного отростка, органа зрения.

Среди обследованных школьников юноши в 2,5 раза чаще, чем девушки, обращались по поводу травм и некоторых других последствий воздействия внешних причин, в 1,5 раза - с болезнями системы кровообращения. Девушки в 1,2 раза чаще обращались по поводу болезней органов дыхания, в 1,4 раза - с болезнями уха и сосцевидного отростка, в 1,8 раза - с болезнями органа зрения, в два раза - с болезнями мочеполовой системы.

Анализ материалов углубленного медицинского осмотра показал, что уровень морфофункциональных отклонений и хронических болезней у школьников составил 120,8 на 100 осмотренных (102,2\% у юношей и 138,6\% у девушек). Уровень патологической пораженности у девушек был до- 
статочно стабилен во всех возрастных группах и колебался в пределах 129,0-144,5 на 100 осмотренных. Заболеваемость по данным углубленного медицинского осмотра юношей 15 лет составила $118,9 \%$, а среди 17 -летних - 90,1\%.

Структура хронических заболеваний, выявленных при углубленном медицинском осмотре подростков-школьников, была представлена по мере убывания: болезнями костно-мышечной системы (нарушения осанки и плоскостопие) $25,4 \%$; глаза и его придаточного аппарата (миопия) - 22,9\%; органов пищеварения (гастриты, дуодениты, функциональные расстройства желчного пузыря) - $18,6 \%$; органов дыхания (хронический тонзиллит) $-14,4 \%$; что в сумме составило $81,3 \%$ от всех хронических болезней.

Уровень патологической пораженности учащихся техникума составил 109,1 на 100 осмотренных. В структуре их заболеваемости первое место занимал класс болезней органов пищеварения $(26,1 \%)$, второе - костно-мышечной $(24,9 \%)$, третье - нервной $(16,6 \%)$ систем, четвертое - органов дыхания (12,9\%). Суммарная доля перечисленных классов составляла $80,5 \%$.

Заболеваемость населения является многовекторной проблемой и зависит от целого ряда социально-гигиенических, медико-биологических факторов. Изучение анкетных данных подростков 15-17 лет, обучающихся в различных образовательных учреждениях, выявило особенности жилищно-бытовых условий, образа жизни, поведенческих факторов риска.

Среди компонентов ресурсной базы любого образа жизни наиболее очевидным представлялась оценка материально-бытовой обеспеченности. Более половины $(56,6 \%)$ обследованных школьников и $63,4 \%$ учащихся техникума считали свое материальное положение удовлетворительным, хорошим - 41,8 и $29,8 \%$, неудовлетворительным - 1,6 и $6,8 \%$ соответственно.

Оценка материального положения во многом обусловливалась условиями проживания $(\mathrm{r}=0,61$; $\mathrm{p}<0,001)$, поскольку именно гигиенические характеристики жилья все больше становятся неотьемлемой частью оценки экономического благосостояния населения. Так, среди учащихся школ и техникума, которые оценили свое материальное благополучие как «хорошее», проживали в неудовлетворительных жилищных условиях 2,4 и $3,4 \%$ соответственно. Среди тех, кто оценивал свое материальное состояние как «неудовлетворительное», в неудовлетворитель-ных условиях (жилая площадь на 1 человека менее $6 \mathrm{~m}^{2}$, неутепленный санитарный узел и др.) проживали 100 и $71,5 \%$ соответственно. На момент опроса $96,1 \%$ школьников проживали в отдельной квартире, $3,3 \%$ - в частном доме, в комнате коммунальной квартиры - 0,6\%; учащиеся техникума: в собственной квартире $-69,2 \%$, в общежитии $-24 \%$, в частном доме $-6,8 \%$ респондентов.

Общеизвестно, что чем выше уровень жизни населения, тем ниже доля расходов на питание, и, наоборот [12]. По данным опроса у большей части респондентов доля расходов на питание составила не менее 55\% семейного бюджета.

Оценка особенностей питания обследуемых учащихся проводилась на основе изучения частоты употребления основных групп пищевых продуктов, а также соблюдения режима питания.

В результате анализа анкет школьников выявлено, что с возрастом уменьшается доля учащихся, получающих физиологически оптимальное 4-5-разовое питание. В группе 15-летних учащихся школ не менее 4-5 раз в день употребляли пищу 17,2\% респондентов, в группе 17-летних $10,1 \%$; среди учащихся техникума 4-5-разовым питанием были обеспечены соответственно 37,0 и 20,7\% подростков. Среди старшеклассников выявлены лица, принимающие пищу не более 2 раз в день $(8,8 \%)$, что не соответствует гигиеническим требованиям; среди учащихся техникума таких лиц было 5,1\%.

Установлено, что ежедневно употребляли мясо и мясные продукты $63,4 \%$ учащихся школ и $58,6 \%$ учащихся техникума. Более трети всех респондентов указали, что мясные продукты входили в рацион 1-2 раза в неделю. В рацион питания более $70 \%$ респондентов колбасные изделия входили 2-3 раза в неделю. Не менее 1 раза в неделю употребляли рыбу 43,4\% школьников и $32,9 \%$ учащихся техникума.

Существенных различий между подростками разных учебных заведений по частоте употребления молока не выявлено. 30,9\% опрошенных школьников и $25,0 \%$ учащихся техникума указали на потребление молока 2-3 раза в неделю, 58,9 и $66,4 \%$ соответственно - 1 раз в неделю. Из группы молочных продуктов в ежедневном рационе подростков в порядке убывания присутствовали сыр, кисломолочные напитки, творог.

Анализ частоты употребления группы продуктов, содержащих углеводы, показал, что более половины (до 70\%) обеих групп учащихся употребляли макаронные изделия не менее 2-3 раз в неделю, картофеля - не менее 2-3 раз в неделю, крупяных изделий - не чаще 1 раза в неделю.

Анализ частоты употребления овощей и фруктов в разные сезоны года позволил установить, что в летне-осенний период подростки больше употребляют свежих овощей и фруктов ежедневно: $75,1 \%$ учащихся школ и $83,6 \%$ учащихся техникума; в зимне-весенний период - 38,7 и $41,8 \%$ соответственно. 
Отмечено большое количество учащихся, употребляющих junk food («нездоровую еду»), к которой относятся фастфуд, чипсы, хрустящий картофель, сухарики, соленый арахис и пр. Только $15,7 \%$ школьников и 21,2\% учащихся техникума указали, что не используют данный вид продуктов в питании, употребляют их 1 раз в месяц - 42,4 и 19,2\%, чаще - 41,9 и 59,6\% соответственно. Газированные напитки периодически появляются в рационе питания у 60,7\% школьников и 43,8\% подростков техникума.

Таким образом, анализ частоты употребления основных групп пищевых продуктов подростками показал дисбаланс по качественному составу пищи. Особенности питания и возможные проблемы с качественным и количественным содержанием пищевого набора большинство опрошенных (89,3\%) связывали с материальным достатком семьи. Получены положительные корреляции сумм семейного бюджета учащихся, затрачиваемых на питание, с частотой употребления мяса $(\mathrm{r}=0,39 ; \mathrm{p}<0,01)$, рыбы $(\mathrm{r}=0,51 ; \mathrm{p}<0,001)$, овощей $(\mathrm{r}=0,42 ; \mathrm{p}<0,01)$, фруктов $(\mathrm{r}=0,36 ; \mathrm{p}<0,01)$ и отрицательная корреляция с частотой употребления картофеля ( $\mathrm{r}=-0,31 ; \mathrm{p}<0,01)$.

Одним из объективных ресурсов, находящихся в распоряжении свободного человека, является время. От того, насколько рационально построен суточный бюджет времени, во многом зависит образ жизни.

Значительная часть суточного времени тратится на ночной сон. Большинство респондентов спали в среднем 7-8 часов в сутки. Продолжительность сна менее 7 часов отмечали 16,4\% школьников и $21,2 \%$ учащихся техникума, более 8 часов - 29,9 и 17,5\% респондентов соответственно. Выявлена тенденция снижения продолжительности сна по мере увеличения возраста обследованных девушек-школьниц. Так, в группе 15-летних школьниц средняя длительность ночного сна составила $8,5 \pm 0,5$ часов, в возрастной группе старше 17 лет $-6,8 \pm 0,7$ часов $(\mathrm{p}<0,05)$.

Самой распространенной ежедневной затратой времени респондентов являлось время, которое затрачивалось на просмотр телепередач и использование Интернета. Большинство школьников (74\%) отметили, что проводили у телевизора не менее 2-3 часов в день. Подростки, получающие профессиональное образование, в 39\% случаев тратили на просмотр телепередач в среднем 1 час в день, в 47,9\% случаев - 2-3 часа.

Анализ результатов проведенного анкетирования показал широкую распространенность использования Интернета среди подростковреспондентов (96\%). Возраст не был связан со временем потребления информации через доступные электронные средства и современные гаджеты ( $\mathrm{r}=-0,48 ; \mathrm{p}<0,05)$, однако статус учебного заведения имел значение $(\mathrm{r}=0,87 ; \mathrm{p}<0,01)$. Средняя продолжительность типичного использования Интернета среди учащихся школ составила $5,8 \pm 1,4$ часов в день, среди учащихся техникума $3,6 \pm 2,0$ часов в день. Больше всего (50-60\%) времени в Интернете респонденты уделяли общению, однако поиск информации, чаты и сетевые игры у подростков также были довольно продолжительны (до 2 часов в день).

Распространенность активного отдыха в виде регулярных занятий физической культурой и спортом в секциях была крайне низка (до 15\% среди учащихся школ, 7,5\% - среди учащихся техникума). Показатели низкой физической активности подростков имели статистически незначимые корреляционные взаимосвязи с возрастом $(\mathrm{r}=-0,47 ; \mathrm{p}<0,05)$, жилищными условиями $(\mathrm{r}=-0,81$; $\mathrm{p}<0,05)$, однако была выявлена прямая корреляционная связь с продолжительностью пользования Интернетом ( $\mathrm{r}=0,63 ; \mathrm{p}=0,001)$. В то же время до 90\% всех респондентов хотели бы повысить двигательную активность, мотивируя это желанием улучшить фигуру (31,8\%), развить физические качества $(30,5 \%)$, укрепить здоровье $(19,1 \%)$, уметь постоять за себя $(10,2 \%)$, общаться и / или иметь друзей $(8,4 \%)$.

Среди неблагоприятных факторов образа жизни по значимости медико-социальных последствий существенная роль принадлежит вредным привычкам.

В группе курящих школьников средний возраст начала курения составил $16,3 \pm 1,6$ года, в группе учащихся техникума $-15,3 \pm 2,2$ года.

Из курящих школьников 48,3\% курили постоянно; 45\% курили 4-6 раз в неделю, 6,7\% - 1-3 раза в неделю. Частота курения у учащихся техникума была следующей: 70,5\% респондентов курили систематически, 29,5\% - 4-6 раз в неделю. Интенсивность курения, измеряемая в количестве сигарет, выкуриваемых в сутки, составила у школьников $8,4 \pm 2,0$ (у девушек - 6,6 $\pm 2,8$ ), в группе юношей техникума - 10,2 $\pm 4,5$.

Отвечая на вопрос «Что повлияло на решение начать курить?», большинство респондентов указали на наличие у них так называемого «поведенческого стереотипа». Так, 54\% школьников и 48\% учащихся техникума ответили, что начали курить, потому что курят друзья; 16\% школьников и $26 \%$ учащихся техникума указали на курение родителей и других родственников в семье; 20\% школьников и 15\% юношей из техникума связали причины курения со стрессом, около 10\% всех опрошенных подростков вообе не задумывались о причинах курения.

Другим распространенным вариантом девиантного поведения подростков является прием ал- 
коголя. В результате анализа распространенности потребления алкоголя обследуемыми подростками выявлено, что 60,8\% школьников и 74,5\% учащихся техникума употребляли те или иные алкогольные напитки в течение последних 6 месяцев.

По данным анкетного опроса определено, что впервые алкоголь подростки пробуют в очень раннем возрасте (от 12 до 15 лет). В то же время средний возраст начала регулярного приема алкогольных напитков среди юношей-школьников составил $15,8 \pm 1,5$ года, девушек-школьниц $15,5 \pm 1,4$ года, учащихся техникума $-15,3 \pm 1,1$ года. Все $100 \%$ респондентов указали, что впервые попробовали алкоголь с друзьями.

На вопрос «Что повлияло на решение впервые попробовать алкоголь?» большинство учащихся школ $(53,4 \%)$ и техникума $(42,1 \%)$ ответили, что «пробовать алкоголь принято»; второй по популярности ответ - «чтобы развеселиться» - указали 32,5 и 41,1\% подростков соответственно. Каждому десятому респонденту алкоголь впервые предложили родители на «семейный праздник», «торжество», «приход гостей».

Среди потреблявших алкоголь у большей части школьников $(64,2 \%)$ случаи употребления были редкими за прошедшие полгода; 35,0\% отметили, что выпивали несколько раз в месяц; 0,8\% - несколько раз в неделю. Среди юношей, потреблявших алкоголь, более половины выпивали с периодичностью несколько раз в месяц и чаще, а среди девушек таковых было менее половины.

Среди потреблявших алкоголь юношей из техникума $53,8 \%$ отметили единичные случаи за последние 6 месяцев; 38,7\% - выпивали несколько раз в месяц; 6,5\% - несколько раз в неделю и $1,0 \%$ - ежедневно.

При анализе предпочтений в видах алкогольных напитков обращает на себя внимание разнообразие употребления подростками алкоголя. Среди учащихся независимо от вида учебного заведения наибольшей популярностью пользовалось пиво (более 50\%). Также юноши отдавали предпочтение крепким спиртным напиткам, коктейлям на основе крепких спиртсодержащих напитков, а девушки - плодовым винам, игристым и шампанским винам, коктейлям.

При изучении факторов риска потребления алкоголя были выявлены положительные корреляционные связи между частотой потребления спиртных напитков и мужским полом ( $\mathrm{r}=0,65$; $\mathrm{p}<0,05)$, курением ( $\mathrm{r}=0,71 ; \mathrm{p}<0,001)$, наличием в семье лиц, злоупотребляющих алкоголем $(\mathrm{r}=0,59$; $\mathrm{p}<0,01)$, «проблемными» отношениями с родителями

$(\mathrm{r}=0,44 ; \mathrm{p}<0,01)$, проживанием в общежитии (для учащихся техникума) ( $\mathrm{r}=0,35 ; \mathrm{p}<0,05)$, наличием хронических заболеваний $(\mathrm{r}=0,33 ; \mathrm{p}<0,05)$, наличием «свободных» денег (r=0,24; $<<0,05)$.

Таким образом, среди обследуемых учащихся установлен рост числа заболеваний, обусловленный действием комплекса причин. Полученные данные диктуют необходимость дальнейшего мониторинга здоровья подростков, реализации комплекса мероприятий по ранней диагностике заболеваний и формированию культуры сохранения здоровья.

Опыт реализации различных профилактических программ, предназначенных только для подростковой аудитории, показал их недостаточную эффективность, что в первую очередь связано с использованием устаревших форм и методов санитарно-гигиенического воспитания. Эффективность профилактической работы зависит от ее регулярного, систематического выполнения, что возможно лишь при обеспечении доступности и постоянного контроля. С этих позиций образовательное учреждение, в котором учащийся находится большую часть своего времени и где формируются довольно прочные связи с взрослым окружением и сверстниками, представляется оптимальным местом проведения профилактической работы среди подростков. Работа может организовываться по принципу функционального медико-профилактического комплекса, объединяющего несколько модулей: лечебнооздоровительный, медико-профилак-тический, санитарно-гигиенический, органи-зационнометодический, информационно-образовательный.

Необходимо сформировать или изменить сложившийся стереотип поведения в отношении здоровья у самих подростков и учащейся молодежи таким образом, чтобы отправной точкой служила не борьба с возникшим заболеванием или обострением, а работа по их предотвращению.

\section{ЛИТЕРАТУРА}

1. Баранов А.А. Состояние здоровья детей в Российской Федерации // Педиатрия. - 2012. - Т.91, № 3. - C. 9-14.

2. Баранов А.А., Намазова-Баранова Л.С., Альбицкий В.Ю., Терлецкая Р.Н., Антонова Е.В. Состояние и проблемы здоровья подростков в России // Пробл. соц. гигиены, здравоохранения и истории медицины. - 2014. - № 6. - С. 10-14.

3. Бокарева Н.А., Скоблина Н.А., Милушкина О.Ю., Бесстрашная Н.А., Сапунова Н.О. Гигиеническая характеристика медико-социальных факторов и образа жизни современных московских школьников // Здоровье населения и среда обитания. 2015. - № 5 (266). - С. 33-36.

4. Елисеев Ю.Ю., Сергеева С.В., Клещчина Ю.В. Комплексные стратегии управления здоровьем детско- 
го населения в эндемичных по содержанию йода районах Саратовского региона // Гигиена и санитария. - 2014. - № 1. - С. 68-70.

5. Елисеев Ю.Ю., Войтович А.А., Дубровина Е.А., Елисеева Ю.В. К оценке функционального состояния организма подростков с различным уровнем здоровья в условиях профессионального обучения // Известия Самарского науч. центра РАН. Социальные, гуманитарные, медико-биологические науки. - 2014. - Т. 16, № 5-2. - С. 850-852.

6. Елисеева Ю.В., Елисеев Ю.Ю., Войтович А.А. Гигиенические аспекты изучения состояния питания учащихся с различным уровнем здоровья // Гигиена и санитария. - 2014. - № 1. - С. 68-70.

7. Клещина Ю.В. Комплексные гигиенические проблемы сохранения здоровья подрастающего поколения // Вестник Рос. военно-медицинской академии. - 2007. - № 4. - С. 75.

8. Коробчанский В.А., Светличный В.Ю. Гигиеническая оценка условий профессионального обучения подростков с различным уровнем социальной адаптации и здоровья // Курск. науч.-практ. вестн. «Человек и его здоровье». - 2014. - № 2. C. 90-93.

9. Кучма В.Р. Охрана здоровья детей и подростков в национальной стратегии действий в интересах детей на 2012-2017 гг. // Гигиена и санитария. 2013. - № 6. - С. 26-30.

10. Кучма В.Р. Формирование здорового образа жизни детей и единого профилактического пространства в образовательных организациях: проблемы и пути решения // Гигиена и санитария. - 2015. - № 6. C. 20-25.

11. Лапин Ю.Е. Государственная политика в области охраны здоровья детей // Здравоохранение в РФ. 2010. - № 1. - С. 14-18.

12. Лисищьын Ю.П. Образ жизни и здоровье. - М. : МГМСУ, 2011. - $192 \mathrm{c.}$

13. Павлов Н.Н., Клещиина Ю.В., Елисеев Ю.Ю. Оценка фактического питания и пищевого статуса современных детей и подростков // Курск. науч.-практ. вестн. «Человек и его здоровье». - 2011. - № 1. С. 128-132.

14. Стулина Д.Д., Архангельская А.Н., Пустовалов Д.А., Куденцова С.Н., Анищенко А.П., Рогозная Е.В., Бурдюкова Е.В., Осадченко И.В., Гуревич К.Г. Поведенческие и неповеденческие факторы риска у курящей молодежи и их влияние на состояние здоровья // Курск. науч.-практ. вестн. «Человек и его здоровье». - 2016. - № 1. С. 101-105.

15. Чичерин Л.П. Медико-социальные аспекты охраны здоровья детей и подростков // Бюллетень Национального научно-исследовательского института общественного здоровья. - 2010. - Вып. 4. C. $12-15$.

16. Perrin J.M., Bloom S.R., Gortmaker S.L. The increase of childhood chronic conditions in the United States // JAMA. - 2007. - Vol. 297, № 24. - P. 2755-2759. 